\title{
Análises anatômicas e da biomassa em plantas de morangueiro cultiva- das in vitro e ex vitro
}

\author{
Eunice O. Calvete; Marlene Azevedo; Marta H. Bordignon; Marilei Suzin \\ UPF, C. Postal 611, 99.001-970 Passo Fundo-RS, E-mail: calveteu@upf.tche.br
}

\begin{abstract}
RESUMO
O presente trabalho foi realizado no laboratório e estufas plásticas da Universidade de Passo Fundo, com o objetivo de caracterizar a morfologia em folhas de morangueiro cultivar Vila Nova, durante o enraizamento in vitro, cultivado em quatro diferentes concentrações de sacarose $(15 ; 30 ; 45$ e 60 g.L.-1 $)$ e, durante a aclimatização ex vitro e in vivo. Os resultados mostraram que concentrações de 30 a 45 g. $\mathrm{L}^{-1}$ otimizaram o desenvolvimento in vitro, no entanto as folhas apresentaram a mesma morfologia nas quatro concentrações de sacarose. As folhas das plantas in vitro apresentaram diferenciação no mesofilo, quando comparadas com as folhas de plantas in vivo, apresentando redução do tecido paliçádico e lacunoso assim como redução da camada de cera da cutícula. Após oito semanas de aclimatização ex vitro, as folhas das plantas apresentaram similar morfologia das folhas das plantas in vitro, porém com algumas características de plantas in vivo.
\end{abstract}

Palavras-chave: Fragaria X ananassa Duch, micropropagação, sacarose, morfologia de folhas, aclimatização.

\begin{abstract}
Anatomic analyses and biomass of strawberry plants cultivated in vitro and ex vitro

This work was carried out at the laboratory and greenhouse of the Universidade de Passo Fundo (Brazil), to evaluate the strawberry leaves morphology of $\mathrm{cv}$. Vila Nova during rooting in vitro (growing on $15 ; 30,45$, and $60 \mathrm{~g} \mathrm{~L}^{-1}$ of sucrose), and to evaluate the strawberry leaves morphology during the acclimatization ex vitro and in vivo. A better in vitro plants development was found by using 30 and $45 \mathrm{~g} \mathrm{~L}^{-}$ ${ }^{1}$ of sucrose, while no differences were found for the leaf morphology in different sucrose concentrations. Leaves from plants grown in vitro showed mesophyl tissues differentiation when compared to the in vivo plants. The latter showed a decrease of the palisade and spongy tissues, as well as, a decrease of the epicuticular wax layer. After eight weeks of acclimatization ex vitro, the leaves showed a similar morphology to the in vitro plant leaves, however, some characteristics of in vivo plants were still present.
\end{abstract}

Keywords: Fragaria Xananassa Duch., micropropagation, sucrose, morphology of leaves, acclimatization.

\section{(Recebido para publicação em 30 de outubro de 2001 e aceito em 13 de maio de 2002)}

$\mathrm{O}$ morangueiro (Fragaria $x$ ananassa Duch.) é uma planta herbácea, rasteira, com características de cultura perene, porém é cultivada como cultura anual. A propagação é vegetativa, através de estolhos que se originam na planta-mãe e enraízam em condições de fotoperíodo longo, temperatura elevada, formando novas plantas.

A produção de mudas desta cultura é uma atividade distinta da produção de frutos, sendo realizada por viveiristas especializados, registrados e fiscalizados pela Secretaria da Agricultura e Abastecimento, envolvendo muita tecnologia. No entanto, muitos produtores de frutos produzem suas próprias mudas. Porém, o ideal é adquirir mudas matrizes, isentas de vírus, produzidas por empresas que utilizam a técnica da micropropagação. As mudas deverão ser mantidas em telado, propagadas em bandejas ou outros recipientes com substrato desinfestado. Posteriormente, essas matrizes devem ser multiplicadas à campo para a obtenção das mudas co- merciais (Assis, 1999).

Segundo Grattapaglia \& Machado (1998), a micropropagação compreende vários estágios: $\mathrm{O}$ estágio zero envolve a seleção de plantas matrizes sadias, desenvolvidas em casa de vegetação. O estágio I refere-se à fase de seleção dos explantes, desinfestação e cultivo em meio sob condições assépticas, com a posterior multiplicação do propágulo por meio de sucessivos subcultivos (Estágio II). A transferência das partes aéreas para o meio de enraizamento e subsequente transplante para o substrato compreendem os Estágios III e IV, respectivamente (Debergh, 1991).

A fase de enraizamento tem como objetivo a formação de raízes adventícias nas partes aéreas provenientes da multiplicação, permitindo assim, o posterior transplantio para condições ex vitro. Alguns autores têm observado aumento na porcentagem de enraizamento para alguns protocolos de aclimatização ex vitro com o incremen- to da concentração de sacarose. Riquelme et al. (1991), estudaram o efeito de várias concentrações de sacarose ( 0 a 60 g.L L $\left.^{-1}\right)$ na etapa de pré-acondicionamento in vitro de plantas de morangueiro, batata, menta e videira. Resultados demonstraram que doses de 30 a 45 g. $\mathrm{L}^{-1}$ foram as mais adequadas durante $\mathrm{o}$ pré-acondicionamento in vitro e posterior sobrevivência durante a fase de aclimatização. Da mesma forma, plantas de gerânio (Pelargonium zonale var. Rubin) multiplicadas in vitro foram transferidas para meios de enraizamento com e sem sacarose. Segundo Aldrufeu (1987), a adição de 20 g.L.-1 de sacarose no meio aumentou a quantidade de plantas de gerânio enraizadas, bem como o número de raízes por planta. Para Calvete (1998), plantas de morangueiro cultivar Campinas produzidas na concentração de 45 g. $\mathrm{L}^{-1}$ de sacarose, apresentaram maior enraizamento e na ausência dessa, não houve desenvolvimento das raízes.

Espaço limitado, baixa irradiação, alta umidade relativa do ar no interior 
dos frascos e trocas gasosas ineficientes são alguns fatores que caracterizam o ambiente de cultivo in vitro. Este meio propicia alta taxa de multiplicação, mas as plantas produzidas diferem anatômica, morfológica e fisiologicamente daquelas plantas desenvolvidas em casa de vegetação e em campo.

Donnelly \& Vidaver (1984) estudaram a anatomia de folhas de framboesa propagadas in vitro e verificaram que estas eram pequenas, com finas camadas de células paliçádicas e contendo menor número de pêlos epidermais do que aquelas formadas in vivo. No entanto, com o desenvolvimento da planta, após o transplante, surgiram folhas anatomicamente semelhantes à testemunha.

Foi realizado, por Waldenmaier (1994), uma análise histológica de folhas de azálea (Rhododendron indica) durante aclimatização de plantas in vitro, onde foram verificadas estruturas mal formadas no mesofilo e pequena cavidade estrutural dos estômatos. $\mathrm{O}$ autor relata que a aclimatização com baixa umidade relativa do ar resultou em aumento tanto na densidade estomática, como na diferenciação da parede celular de células do parênquima paliçádico e lacunoso. Segundo Pierik (1990), plantas provenientes do cultivo in vitro apresentam células paliçádicas menores e em menor quantidade.

Wardle et al. (1983) demonstraram, com couve-flor (Brassica oleracea var botrytis), que uma diminuição na umidade relativa in vitro produziu uma formação de cutícula mais espessa, o que permitiu uma menor transpiração celular. A maioria das espécies de plantas cultivadas in vitro têm, geralmente, a cutícula pouco desenvolvida, devido à alta umidade relativa (90 a 100\%) que ocorre in vitro. As folhas das plantas in vitro são geralmente finas, tenras e fotossinteticamente pouco ativas; por isto, mal adaptadas às condições que irão encontrar na aclimatização (Pierik, 1990). Conhecendo as alterações morfológicas de plantas desenvolvidas in vitro, pode-se manipular o ambiente durante a aclimatização ex vitro. O presente trabalho objetivou caracterizar a morfologia em folhas de morangueiro cultivar Vila Nova, durante o enraizamento in vitro, cultivadas em quatro diferentes concentrações de sacarose $\left(15 ; 30 ; 45\right.$ e 60 g.L $\left.\mathrm{L}^{-1}\right)$ e, durante a aclimatização ex vitro e in vivo.

\section{MATERIAL E MÉTODOS}

O trabalho foi desenvolvido no laboratório e em estufas da Universidade de Passo Fundo, durante o período de novembro de 1999 à novembro de 2000.

Isolou-se gemas apicais de morangueiro, cv. Vila Nova e, posteriormente as mudas obtidas foram transferidas para frascos $(300 \mathrm{ml})$, com cerca de $60 \mathrm{ml}$ do meio básico de MS (Murashige \& Skoog, 1962) suplementado com 2 mg. $\mathrm{L}^{-1}$ de benzilaminopurina (BAP) e $0,5 \mathrm{mg} . \mathrm{L}^{-1}$ de ácido giberélico $\left(\mathrm{GA}_{3}\right)$, $30 \mathrm{~g}$ de sacarose e $6 \mathrm{~g}$ de ágar. Os frascos com as plantas foram colocados em sala de crescimento com temperatura ambiente de $25 \pm 2^{\circ} \mathrm{C}$, fotoperíodo de 16 horas e intensidade luminosa de \pm 2000 lux. Vários ciclos de multiplicação foram efetivados, até atingir o número desejado de mudas.

As mudas selecionadas na etapa anterior foram colocadas para enraizar em meio básico MS suplementado com 0,05 mg. $L^{-1}$ de BAP e $6 \mathrm{~g}$ de ágar, em diferentes concentrações de sacarose $(15$; 30; 45 e 60 g. $\left.\mathrm{L}^{-1}\right)$. O pH do meio de cultura foi ajustado para 5,8 com $\mathrm{NaOH}$, antes da autoclavagem, em todas as etapas da micropropagação. O delineamento experimental utilizado foi de blocos casualizados (4). Cada parcela (frasco) constou de 5 plantas, perfazendo o total de 320 explantes. Após quatro semanas na câmara de crescimento foram avaliadas as características: massa fresca e seca de folhas e raízes e alterações morfológicas das folhas. A massa seca foi obtida através da secagem em estufa a $65^{\circ} \mathrm{C}$ até peso constante. A matéria seca da parte aérea e da raiz das plantas de morangueiro foram determinadas em uma balança digital analítica (Sartorius).Os resultados obtidos foram submetidos à análise de variância e de regressão.

Para o experimento ex vitro foram produzidas 120 mudas em meio MS suplementados de $0,05 \mathrm{mg} . \mathrm{L}^{-1}$ de BAP, $6 \mathrm{~g}$ de ágar e 45 g. $\mathrm{L}^{-1}$ de sacarose. Após 30 dias foram transferidas para bandejas de isopor com 72 células, com o substrato constituído por casca de arroz carbonizada $(30 \%)$, vermicomposto $(25 \%)$, solo mineral (latossolo vermelho escuro (35\%)) e vermiculita (10\%), sendo utilizado o sistema de irrigação por nebulização.

Para analisar comparativamente as características anatômicas, foram realizadas avaliações morfológicas em mudas desenvolvidas durante a fase do enraizamento in vitro (folhas retiradas do tubo de ensaio), durante a aclimatização ex vitro (folhas coletadas em porções inferiores das mudas, após oito semanas de crescimento em estufa agrícola) e in vivo (plantas desenvolvidas em condição de ambiente natural).

As análises morfológicas das folhas de morangueiro iniciaram com a coleta e clarificação do material, a qual foi feita em hipoclorito de sódio (20\%), até as mesmas apresentarem-se transparentes (sem clorofila), segundo metodologia de Kraus \& Arduin (1997). Os cortes foram efetuados à mão livre e o procedimento de coloração utilizado foi a combinação de azul de astra e fucsina básica, nas concentrações de $0,5 \%$ conforme metodologia descrita por Roeser (1962) apud Kraus \& Arduin (1997). A montagem foi em glicerina $50 \%$ e a lutagem com esmalte incolor. Foi realizada a observação da anatomia foliar na fase do enraizamento in vitro e durante aclimatização ex vitro. Os estudos predominaram nos tecidos componentes do mesofilo foliar e de revestimento. Os cortes foram fotografados em fotomicroscópio Olympus Bx50.

\section{RESULTADOS E DISCUSSÃO}

Os resultados obtidos por meio da análise de variância, para as quatro diferentes concentrações de sacarose (15; $30 ; 45$ e 60 g. $\mathrm{L}^{-1}$ ) no meio de enraizamento in vitro, demonstraram que para as características massa fresca e seca aérea houve um comportamento linear, onde doses crescentes de sacarose promoveram acréscimos de 1,4 e $0,5 \mathrm{mg}$ para a biomassa fresca e seca, respectivamente (Figura 1). Para a característica massa fresca da raiz houve um incremento até a dose de 30 g. $\mathrm{L}^{-1}$, diminuindo na de 45 e 60 g.L - $^{-1}$, evidenciando um comportamento quadrático, onde o pon- 
to de máximo crescimento corresponde a dose 43,4 g.L.-1 de sacarose (Figura 2). No entanto, na massa seca da raiz, o comportamento foi linear, verificandose aumento de $0,15 \mathrm{mg}$ para cada grama de sacarose adicionada ao meio (Figura 2). Esses resultados demonstraram que as plantas em condições in vitro necessitam de fontes exógenas de açúcar e que, para a cultivar Vila Nova, as doses entre 30 e 45 g. $\mathrm{L}^{-1}$ foram as mais indicadas. Resultados similares foram obtidos em trabalhos realizados, anteriormente, por Azevedo et al., (1999) com esta mesma cultivar e por Calvete (1998), com a cultivar de morango Campinas.

Riquelme et al. (1991) ao estudarem o efeito de várias concentrações de sacarose ( 0 a 60 g. $\left.\mathrm{L}^{-1}\right)$ na etapa de préacondicionamento in vitro de plantas de morangueiro, menta e videira, obtiveram resultados similares. Os autores verificaram que para essas espécies, as doses de 30 a 45 g.L. $\mathrm{L}^{-1}$ foram as mais adequadas durante o pré-acondicionamento in vitro e posterior sobrevivência durante a fase de aclimatização.

Para promover fotoautotrofismo nas plantas in vitro, Debergh (1991) sugere a omissão de sacarose no meio. Langford \& Wainwright (1987) afirmam que o cultivo fotoautotrófico de células e órgãos tem sido buscado por muitos pesquisadores, mas poucos resultados foram encontrados neste sentido. Provavelmente, seria necessário modificar a intensidade de luz e a concentração de $\mathrm{CO}_{2}$ (Arai et al., 1991). Isso sugere que a intensidade luminosa nas câmaras de cultura, estava muito abaixo da faixa necessária para ativar as moléculas de clorofila para a síntese de glicose e, segundo Debergh (1991) nessas condições de cultivo in vitro plantas micropropagadas não são fotoautotróficas, mas mixotróficas ou heterotróficas.

Folhas de plantas de morangueiro cultivadas in vitro e ex vitro apresentaram-se menores e delgadas, comparadas às cultivadas in vivo. Donnely \& Vidader (1984), também encontraram esses aspectos em estudos realizados com framboesa vermelha. As seções transversais de folhas de plantas in vitro, obtidas em diferentes concentrações de sacarose $\left(15 ; 30 ; 45\right.$ e 60 g.L L $\left.^{-1}\right)$ no meio

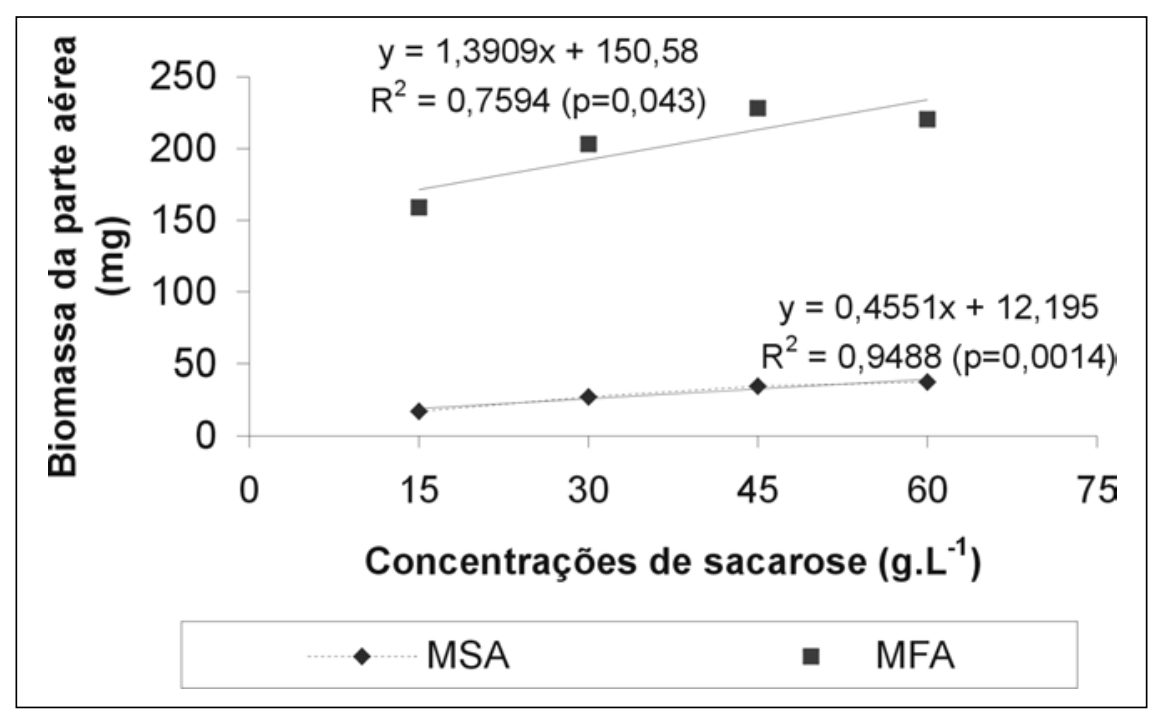

Figura 1. Massa fresca (MFA) e seca (MSA) da parte aérea de plantas de morangueiro $c v$. Vila Nova propagadas in vitro, após o período de 30 dias. Passo Fundo, UPF, 2000.

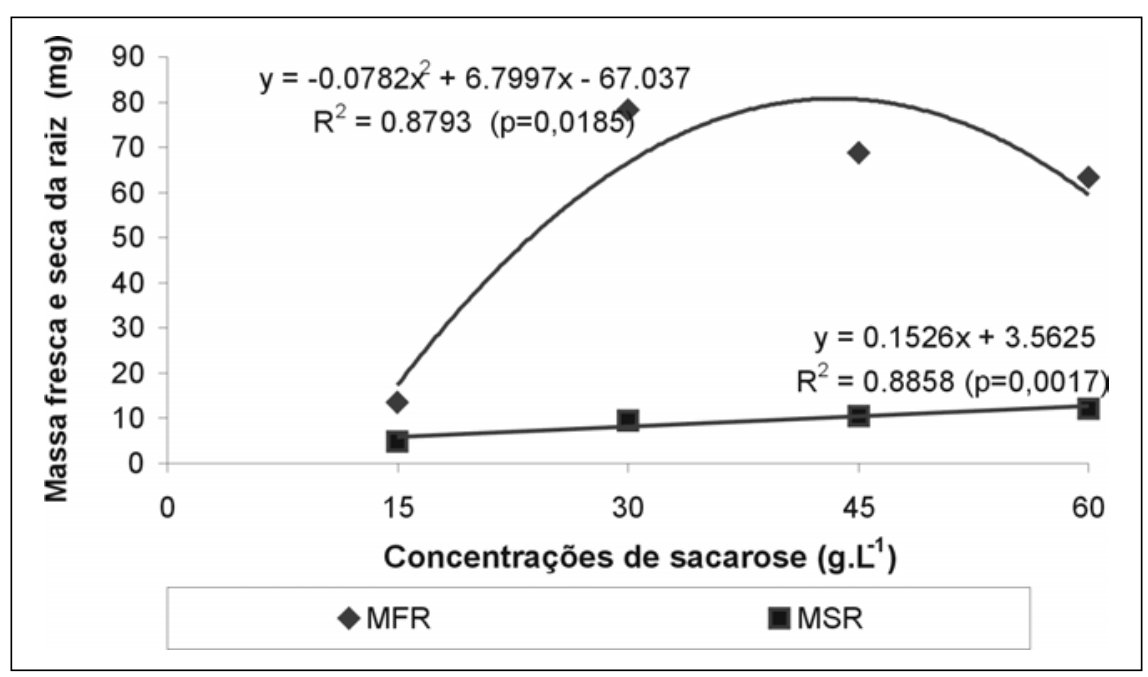

Figura 2. Massa fresca (MFR) e seca (MSR) da raiz em plantas de morangueiro $c v$ Vila Nova propagadas in vitro, após o período de 30 dias. Passo Fundo, UPF, 2000.

de cultura, não apresentaram diferenças marcantes na organização dos tecidos.

Folhas desenvolvidas in vitro na concentração de 45 g. $\mathrm{L}^{-1}$ de sacarose (Figura 3) mostraram uma fina camada de cutícula depositada sobre a epiderme, apresentando uma única camada de células em ambas as faces. Uma das funções da cutícula é proteger a planta contra a perda de umidade. A disposição da mesma pode ser afetada pela intensidade da luz e pela disponibilidade da água (Mauseth, 1988). A fina camada de cutícula das plantas in vitro, demonstrou que o ambiente no qual a planta se desenvolveu não estimulou o aparecimento de uma camada mais espessa, já que as condições de umidade existentes no frasco não exigiram da planta tal formação. Igualmente Wetzstein \& Sommer (1983) relataram que, em estudos realizados com Liquidambar styraciflua, embora a morfologia da cera seja um controle genético, a configuração e distribuição das ceras podem ser modificas pelas condições ambientais e que a dimensão e densidades são afetadas pela luz, temperatura e umidade.

$\mathrm{O}$ mesofilo das folhas in vitro mostrou-se diferenciado no parênquima paliçádico e lacunoso. O primeiro localizado na superfície adaxial e o lacunoso na face abaxial, caracterizando a anatomia dorsiventral da folha (Fahn, 1990). 


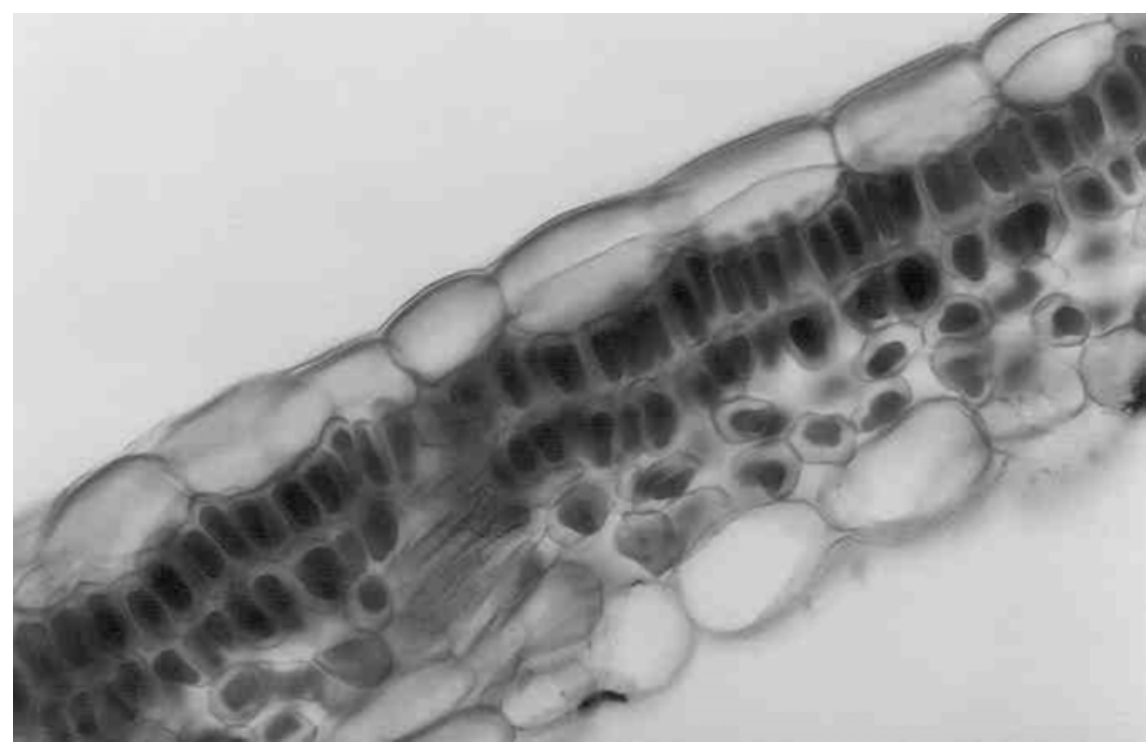

Figura 3. Seção transversal da lâmina foliar do morangueiro $c v$ Vila Nova, durante a fase de enraizamento in vitro em meio de cultura contendo $45 \mathrm{~g} . \mathrm{L}^{-1}$ de sacarose, após período de 30 dias (Aumento: 100X ). Passo Fundo, UPF, 2000.

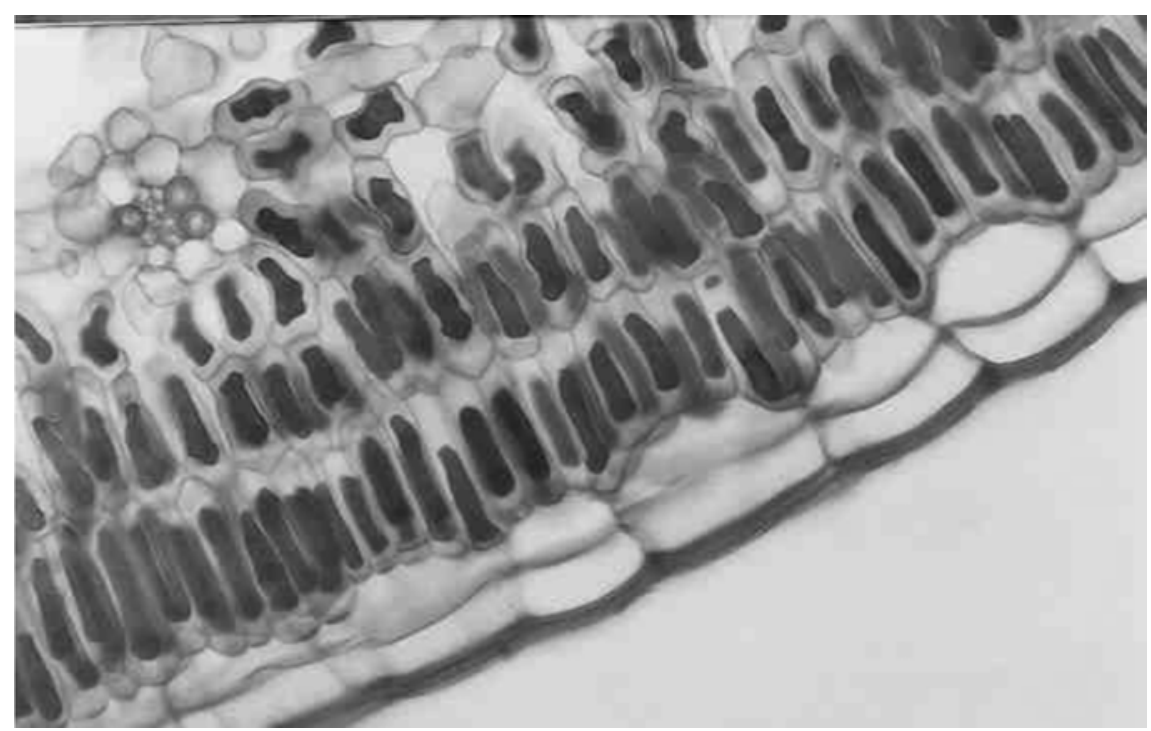

Figura 4. Secção transversal de lâmina foliar de morangueiro $c v$ Vila Nova, cultivada em condições ambientais (in vivo) ( Aumento: 200 X). Passo Fundo, UPF, 2000.

O parênquima paliçádico das plantas in vitro apresentaram, nas quatro concentrações de sacarose, a mesma distribuição nos tecidos, sendo uma camada com células justapostas e uma segunda ainda em disposição vertical porém, com espaços maiores entre elas (Figura 3). Similarmente Donnely \& Vidaver (1984) relataram que as folhas in vitro de framboesa vermelha apresentavam uma camada de células paliçádicas, enquanto as folhas in vivo duas ou mais camadas. O parênquima lacunoso apresentou células de forma arredondadas, comparadas às células do parênquima mia. O nível pode depender do número ou estádio das folhas formadas no meio de cultura.

A epiderme apresentou-se na face adaxial com duas camadas e na abaxial com apenas uma. Tricomas glandulares foram detectados por toda a extensão do tecido de revestimento, principalmente na superfície adaxial. Porém, segundo Donnely \& Vidaver (1984) o mesofilo foliar de framboesa vermelha mostrou os parênquimas paliçádicos e lacunoso numa disposição correspondente à folha in vitro. A epiderme das folhas in vivo com duas camadas de células na superfície adaxial mostrou a cutícula semelhante às plantas in vitro e ex vitro. $\mathrm{Na}$ face abaxial o tecido apresentou apenas uma camada de células (Figura 4). O mesofilo apresentou-se diferenciado em parênquima clorofiliano paliçádico e lacunoso, sendo o paliçádico com duas camadas caracteristicamente justapostas e uma terceira camada também de células alongadas, mas com maiores espaços entre elas. Na mesma figura observa-se o parênquima lacunoso com células do tipo braciforme com espaços intercelulares esquizógenos entre as mesmas. A espessura da folha mostrouse com um um número maior de camadas celulares comparadas com a morfologia da folha in vitro e ex vitro. Waldenmaier (1994) em estudos com folhas de Rhododendron, declara que folhas com dois anos possuiam o tecido paliçádico com duas ou três camadas, em contraste com as folhas in vitro que tinham somente uma camada desse tecido. $\mathrm{O}$ autor relata ainda que as folhas no estádio de aclimatização apresentaram características similares com as in vitro.

Pelo exposto, observou-se que durante o enraizamento in vitro existe a necessidade de suplementar o meio com uma fonte exógena de açúcar, sendo estabelecidas concentrações de 30 a 45 g. $\mathrm{L}^{-1}$ para o cultivo de morangueiro $c v$. Vila Nova. As folhas in vitro mostraramse pequenas, com finas camadas de cera e de células paliçádicas, apresentando mesma morfologia na folha, quando desenvolvidas em diferentes concentrações de sacarose. Em vista disso, um ambiente semelhante ao in vitro, com posterior ajuste gradual na diminuição 
de umidade e aumento da luminosidade nas diferentes etapas de crescimento ex vitro, pode aumentar a taxa de sobrevivência em mudas de morangueiro cultivar Vila Nova, durante a aclimatização.

\section{LITERATURA CITADA}

ALDRUFEU, A. Rooting and acclimatization of Pelargonium zonale plantlets. Acta Horticulturae, v. 212, p. 361-366, 1987.

ARAI, S.; ASAO, H.; KOBATAKE, H. The effect of $\mathrm{CO}_{2}$ enrichment on the growth and quality of strawberry plantlets regenerated from a shoot-tip culture. Bulletim of the Nara Agricultural Experiment Station, n. 22, p. 9-16, 1991.

ASSIS, M. Sanidade do material vegetativo na produção de mudas de morangueiro: IN: DUARTE FILHO, J.; CANÇADO, G.M.A.; REGINA, M.A.; ANTUNES, L.E.C.; FADINI, M.A. (eds.) Morango:Tecnologia de produção e processamento. Caldas:Suprema,1999. p. 65-71. AZEVEDO, M.M.; CALVETE, E.O.; SUZIN, M. AUGUSTIN, L. Efeito da concentração de sacarose na etapa de pré-acondicionamento de morangueiro. In: CONGRESSO NACIONAL DE BOTÂNICA, 50., 1999, Blumenau. Anais.Blumenau: FURB, 1999. p. 135.
CALVETE, E.O. Concentração de sacarose in vitro e seleção de substratos para aclimatização ex vitro de morangueiro cv. Campinas (Fragaria $\mathrm{X}$ ananassa Duch.). Porto Alegre: UFRGS, 1998.108 p. (Tese doutorado).

DEBERGH, P.C. Aclimatization techniques of plants from in vitro. Acta Horticulturae, v. 289, p 291-300, 1991.

DONNELY, D.J.; VIDAVER, W.E. Leaf anatomy of red raspberry transferred from cultured to soil Journal of the the American Society for Horticultural Science, v. 109, n. 2, p. 172-176, 1984.

FAHN, A. Plant Anatomy. Menlo Park: The Benjamin/Cummings, 1990. 560 p.

GRATTAPAGLIA, D.; MACHADO, M.A.; Micropropagação. In: TORRES, A.C.; CALDAS, L.S.; BUSO, J.A.( eds.) Cultura de Tecidos e Transformação Genética de Plantas. Brasília: EMBRAPA-SPI/Embrapa-CNPH, 1998. p. 183260.

KRAUS, J.E.; ARDUIN, M. Manual básico de métodos em morfologia vegetal. Rio de Janeiro: EDUR, 1997. 198 p.

LANGFORD, P.J.; WAINWRIGHT, S. Effects of sucrose concentration on the photosynthesis ability of rose shoots in vitro. Annals of Botany, v. 60, p. 633-640, 1987.
MAUSETH, J. Plant Anatomy. Inglaterra: Pergaman-Press, $1988.588 \mathrm{p}$.

MURASHIGE, T.; SKOOG F.A. Revised medium for rapid growth and bio assays with tobacco tissue cultures. Physiologia Plantarum, n. 15, p. 473497, 1962.

PIERIK, R.L.M. Cultivo in vitro de las plantas superiores. Madrid: Mundi-Prensa, 1990. $326 \mathrm{p}$. RIQUELME, C.; GUIÑAZU, M.E.; TIZIO, R. Pre-acondicionamento y aclimataccion en condicciones de invernáculo de plántulas micropagadas de frutilla, menta, papa y vid. Phyton, v. 52, n. 1, p. 73-82, 1991

WALDEMAIER, S. Histological analyses of Rhododendron leaves during acclimatization of in vitro plants. Acta Horticulturae, v. 364, p. 53-60, 1994.

WARDLE, K.; DOBBS, E.B.; SCHORT, K.C. Invitro acclimatization of asseptically cultured plantlets to humidity. Journal of the American Society for Horticulturae Science, v. 108, n 3, p. 386-389, 1983.

WETSTEIN, H; SOMMER, H. Scanning eletron microscopy of in vitro cultures Liquidambar Styraciflua plantlets during acclimatization. Journal of the American Society for Horticulturae. v. 118, n. 3, p. 419-424, 1983. 